\title{
DZIAŁALNOŚĆ TURYSTYCZNA PODMIOTÓW GOSPODARCZYCH NA TERENIE WOJEWÓDZTWA WIELKOPOLSKIEGO W ROKU 2008
}

\author{
ANNA PRZYBYLSKA \\ Zakład Centrum Turystyki i Reakreacji, Uniwersytet im. Adama Mickiewicza
}

\begin{abstract}
Tourist industry stimulates economic growth of a region, facilitates development of business and creates new jobs. Service of this industry increases economic activity and creates additional income for local communities.

Steady increase of tourist industry is observed in the Wielkopolska region. This study analyses newly established, existing and liquidated (in 2008) tourism-related businesses, including accommodation and catering. The analysis is based on data obtained from the Central Office of Statistics (GUS), including data published by the Regional Data Bank of GUS.

Research shows, that over 97\% incorporated economic subject acting in touristic section, belongs to private sector. This number is strictly related from administrative status of commune. Number of economic subject showing food services and dormitory is strictly related with largeness of administrative district. Number of such object predominates in region of Poznań. We can observe upward trend in considerably widest range of employment in hotels than in other sections of tourism.
\end{abstract}

Keywords: Voivodship of Great Poland, business enterprises, tourist activity

Celem artykułu była ocena zróżnicowania usług w sektorze turystycznym ze względu na wydzielone subregiony w województwie wielkopolskim. Pozwoliło to na wskazanie dysproporcji pomiędzy poszczególnymi działami w sekcji I w zależności od wielkości subregionu i obecności ośrodka miejskiego.

Do zrealizowania postawionego celu wykorzystano dane statystyczne znajdujące się w bazie Głównego Urzędu Statystycznego, wykorzystane na potrzeby przygotowywanej w roku 2008 Ekspertyzy dla Departamentu Gospodarki Urzędu Marszałkowskiego w Poznaniu.

\section{PRZEDSIĘBIORSTWA TURYSTYCZNE W UJĘCIU TEORETYCZNYM}

Podmiot gospodarki narodowej to podmiot stosunków cywilnoprawnych prawa polskiego wyposażony $\mathrm{w}$ autonomię prawną, ekonomiczną i finansową, 
realizujący określoną przez siebie działalność, będący osobą prawną, jednostką organizacyjną niemającą osobowości prawnej albo osobą fizyczną prowadzącą działalność gospodarczą ${ }^{1}$.

Prawo działalności gospodarczej wprowadziło pojęcie „przedsiębiorcy” (zwanego początkowo przez ustawę z 1988 r. podmiotem gospodarczym). Ustawa ta definiuje przedsiębiorcę jako osobę fizyczną lub prawną bądź spółkę prawa handlowego niemającą osobowości prawnej, a także wspólników spółki cywilnej w zakresie wykonywanej przez nich działalności gospodarczej, która zawodowo i we własnym imieniu podejmuje i wykonuje działalność gospodarczą $w$ rozumieniu ustawy ${ }^{2}$. Rozszerzając definicję przedsiębiorcy o prowadzoną przez niego działalność, należy przez przedsiębiorstwo rozumieć podstawową jednostkę organizacyjną gospodarki, która służy zaspokajaniu potrzeb społecznych i jest tworzona w celu osiagania efektów ekonomicznych przez produkcję dóbr, świadczenie usług lub inną działalność. Jest samodzielną i samofinansującą się jednostką gospodarczą posiadającą osobowość prawną (Duraj 2000).

W turystyce najczęściej przedsiębiorstwo turystyczne definiowali: A. Rapacz (1994), M. Bednarska, G. Gołembski, E. Markiewicz, M. Olszewski (2007). W artykule ze względu na przyjęty statystyczny charakter opracowania przyjęto definicje L. Mazurkiewicz (2002), określającą przedsiębiorstwo turystyczne jako każdą organizację utrzymującą się ze sprzedaży produktów turystycznych.

\section{ZMIANA KLASYFIKACJI PKD W SEKCJI I - DZIAŁALNOŚĆ ZWIAZZANA Z ZAKWATEROWANIEM I USŁUGAMI GASTRONOMICZNYMI}

Polska Klasyfikacja Działalności (PKD) 2007 zawiera zmiany, które zostały wprowadzone w klasyfikacji Organizacji Narodów Zjednoczonych - International Standard Industrial Classification of all Economic Activities ISIC Rev. 4 (Międzynarodowej Standardowej Klasyfikacji Rodzajów Działalności) oraz klasyfikacji Unii Europejskiej - Statistical Classification of Economic Activities in the European Community NACE Rev. 2 (Statystycznej Klasyfikacji Działalności Gospodarczych w UE) (Dz.Urz. UE L 393 z 30.12.2006 r., s. 1). Konieczność zmian klasyfikacji wynikała z:

- potrzeby zwiększenia harmonizacji klasyfikacji na poziomie międzynarodowym, umożliwiającej szerszą wymianę informacji,

\footnotetext{
${ }^{1}$ Ustawa z 29.06.1995 r. o statystyce publicznej, Dz.U. Nr 88, poz. 439.

${ }^{2}$ Ustawa z 19.11.1999 r., Prawo działalności gospodarzącej, Dz.U. z 17.12.1999 r. Nr 101, poz. 1178 .
} 
- zachodzących zmian ekonomicznych i gospodarczych, a w szczególności rozwoju nowych technologii i rodzajów działalności ${ }^{3}$.

Wprowadzone zmiany polegały przede wszystkim na uszczegółowieniu klasyfikacji, zwłaszcza w przypadku działalności produkcyjno-usługowej, na skutek pojawiających się nowych gałęzi przemysłu i usług. Dokonane zmiany miały różnorodny charakter. Zmieniono brzmienia niektórych grupowań, co wynikało najczęściej ze zmiany ich zakresu. Część podklas została przesunięta do innych sekcji, działów czy grup, zmieniając w ten sposób ich zakresy. Ponadto, utworzone zostały nowe grupowania dla działalności, które do tej pory nie były wyodrębnione w klasyfikacji. Zostały one wyszczególnione bądź na skutek wzrostu ich znaczenia w gospodarce światowej/krajowej, bądź w związku z pojawieniem się nowych rodzajów działalności w wyniku postępu technologicznego.

W zakresie działalności związanej z zakwaterowaniem i usługami gastronomicznymi nastąpiło przesunięcie sekcji $\mathrm{H}$ obejmującej hotele i restauracje do nowo utworzonej sekcji I. Sekcja ta obejmuje zapewnienie krótkotrwałego pobytu, łącznie $\mathrm{z}$ wyżywieniem przeznaczonym do bezpośredniej konsumpcji. Chcąc odzwierciedlić zróżnicowaną specyfikę i specjalizację prowadzonej działalności, dokonano uszczegółowienia sekcji I poprzez rozbicie dotychczas istniejącego działu 55 - Hotele i restauracje (PKD 2004) na dwa działy: 55 Zakwaterowanie i 56 - Działalność ustugowa zwiqzana z wyżywieniem (PKD 2007) (ryc. 1).

\section{PODMIOTY GOSPODARKI NARODOWEJ W WOJEWÓDZTWIE WIELKOPOLSKIM}

W województwie wielkopolskim jest zarejestrowanych ogółem 361046 podmiotów gospodarki narodowej $\mathrm{w}$ rejestrze REGON, z czego do sektora prywatnego należy trochę ponad $97 \%$ a do sektora publicznego niespełna $3 \%$. $47,7 \%$ wszystkich podmiotów gospodarczych zlokalizowanych jest w gminach wiejskich, mniej w gminach miejsko-wiejskich $(34,2 \%)$ a najmniejsza liczba na terenie gmin wiejskich (niespełna 19\%). Rozkład procentowy udziału sektora publicznego w stosunku do sektora prywatnego nie odbiega zasadniczo przy rozróżnieniu statusu gminy (tzn. miejska, miejsko-wiejska, wiejska), od ogólnego udziału podmiotów gospodarczych dla tych dwóch sektorów dla województwa wielkopolskiego (oscyluje w granicach: $97 \%$ dla sektora prywatnego i około 3\% dla sektora publicznego) (tab. 1, 2).

${ }^{3}$ Polska Klasyfikacja Działalności PKD, Załącznik do rozporządzenia Rady Ministrów z dnia 24.12.2007, Dz.U. 251, poz. 1885 , s. 5 

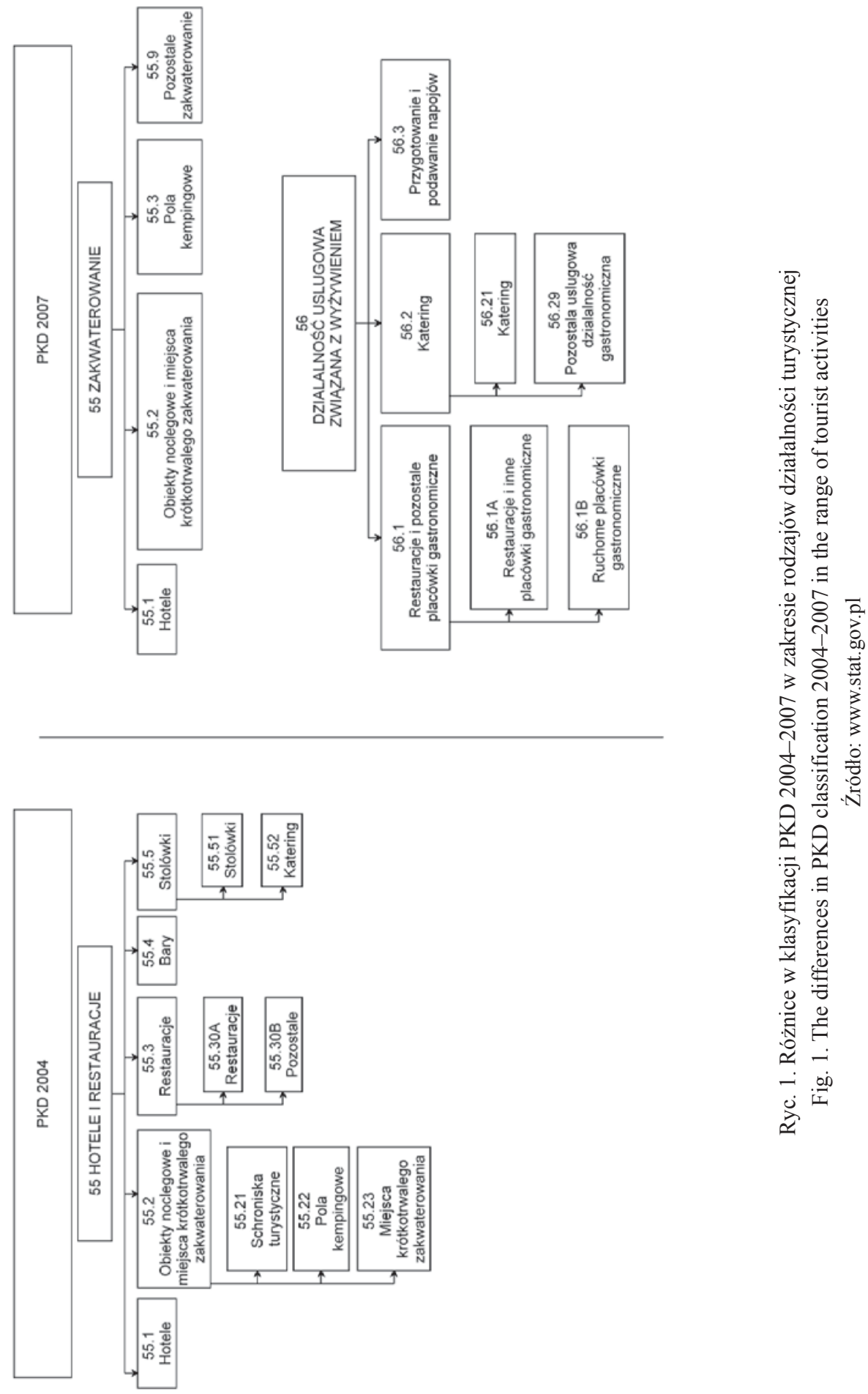
Tabela 1. Procentowy udział sektora publicznego i prywatnego z uwzględnieniem statusu gmin województwa wielkopolskiego

Table 1. Percent participation of sectors public and private with taking into consideration of status of commune in Wielkopolska

\begin{tabular}{lccc}
\hline $\begin{array}{c}\text { Sektor gospodarki } \\
\text { narodowej }\end{array}$ & Gminy miejskie & $\begin{array}{c}\text { Gminy } \\
\text { miejsko-wiejskie }\end{array}$ & Gminy wiejskie \\
\hline Sektor publiczny & 2,4 & 2,9 & 3,1 \\
Sektor prywatny & 97,6 & 97,1 & 96,9 \\
\hline
\end{tabular}

Podmioty gospodarki narodowej zarejestrowane w sekcji skupiają swoją działalność przede wszystkim w zakresie sektora prywatnego, bo aż 99,7\% podmiotów gospodarczych z prawie 23 tys. zarejestrowanych.

Tabela 2. Podmioty gospodarki narodowej w sektorze publicznym sekcji I

Table 2. Subjects of national economies in public sector of section I

\begin{tabular}{llll}
\hline & \multicolumn{2}{c}{ Powiaty } & \\
\hline chodzieski & 2 & ostrzeszowski & 1 \\
czarnkowsko-trzcianecki & 1 & pilski & 2 \\
gnieźniński & 4 & pleszewski & 3 \\
jarociński & 2 & poznański & 6 \\
kępiński & 1 & szamotulski & 1 \\
kolski & 2 & średzki & 1 \\
krotoszyński & 3 & turecki & 1 \\
nowotomyski & 1 & wagrowiecki & 2 \\
obornicki & 1 & wrzesiński & 1 \\
ostrowski & 4 & złotowski & 1 \\
\hline & m. Kalisz & 3 \\
& m. Konin & 3 & \\
& m. Leszno & 1 & \\
& m. Poznań & 13 \\
\hline
\end{tabular}

Źródło: Główny Urząd Statystyczny, Poznań 2008

\section{PRZEDSIĘBIORSTWA TURYSTYCZNE W WOJEWÓDZTWIE WIELKOPOLSKIM W SYSTEMIE REGON}

Największy wpływ na rozwój turystyki, ze względu na tworzenie ku temu warunków ma gmina. Dlatego też w ostatnim czasie turystyka stała się jedną z ważniejszych dziedzin gospodarki polskich gmin (Szwichtenberg 2006). Ze względu 
na dostępność danych i ich charakter, aby zapewnić większą porównywalność wyników, wykorzystano jednostki administracyjne nadrzędne w stosunku do gminy - powiaty. W pracy posłużono się danymi statystycznymi opracowanymi przez Urząd Statystyczny w Poznaniu, uwzględniające liczbę podmiotów oraz liczbę zatrudnionych w rejestrze REGON (stan na 30.11.2008 r.).

Charakterystyczne rodzaje działalności turystycznej w Wielkopolsce, które zostały objęte sprawozdawczością statystyczną według Europejskiej Klasyfikacji Działalności, zestawiono w tabeli 3.

Tabela 3. Rodzaje działalności oraz liczba zatrudnionych w sektorze turystyki w Wielkopolsce według GUS

Table 3. Kind of activities and staff level in sector of tourism in Wielkpolska according to GUS

\begin{tabular}{clcc}
\hline L.p. & \multicolumn{1}{c}{ Rodzaj działalności według EKD } & $\begin{array}{c}\text { Liczba } \\
\text { podmiotów }\end{array}$ & $\begin{array}{c}\text { Liczba } \\
\text { zatrudnionych }\end{array}$ \\
\hline 1. & 55. Hotele i restauracje & 8459 & 27921 \\
2. & $\begin{array}{l}\text { 55.1. Hotele } \\
\text { 55.2. Obiekty noclegowe turystyki i miejsca }\end{array}$ & 393 & 4055 \\
3. & 621 & 2034 \\
& $\begin{array}{l}\text { krótkotrwałego zakwaterowania, pozostałe } \\
\text { 4. }\end{array}$ & & \\
55.3. Restauracje i pozostałe placówki & 3293 & 12079 \\
5. & 55.4. Bary & 3082 & 7531 \\
6. & 55.5. Działalność stołówek i katering & 1070 & 2222 \\
\hline
\end{tabular}

Źródło: Główny Urząd Statystyczny, Poznań 2008

Wykonana analiza wskazała na 16918 zarejestrowanych podmiotów oraz 55842 zatrudnionych w badanych przedsiębiorstwach turystycznych.

Analizie poddano przedsiębiorstwa turystyczne w ujęciu powiatowym oraz subregionalnym. Podział na subregiony obejmował sześć jednostek: poznańską, pilską, konińską, kaliską, nowotomyską oraz leszczyńską (ryc. 2). Głównym czynnikiem delimitacji był zbliżony charakter uwarunkowań rozwoju turystyki oraz występowania ośrodka centralnego, stanowiącego zasadniczy obszar działalności przedsiębiorstw turystycznych oraz punkt zainteresowania turystów.

Największa liczba przedsiębiorstw turystycznych w Wielkopolsce rozwinęła swoją działalność w zakresie branży żywieniowej. Placówek tego typu najwięcej jest w powiatach: poznańskim, pilskim, ostrowskim oraz gnieźnieńskim. Najmniejszą bazą żywieniowa charakteryzują się powiaty: kaliski (51), ostrzeszowski (66), pleszewski (72) i turecki (75). Pozostałe powiaty odznaczają się zbliżoną liczbą obiektów gastronomicznych. Liczba podmiotów gospodarczych świadczących usługi noclegowe jest ściśle związana z wielkością powiatu: i tu analogicznie, jak w przypadku bazy żywieniowej przoduje powiat poznański, a znacznie mniejszą liczbę podmiotów gospodarczych odnotowuje się w powiatach: gnieźnieńskim, pilskim oraz nowotomyskim (tab. 4). 


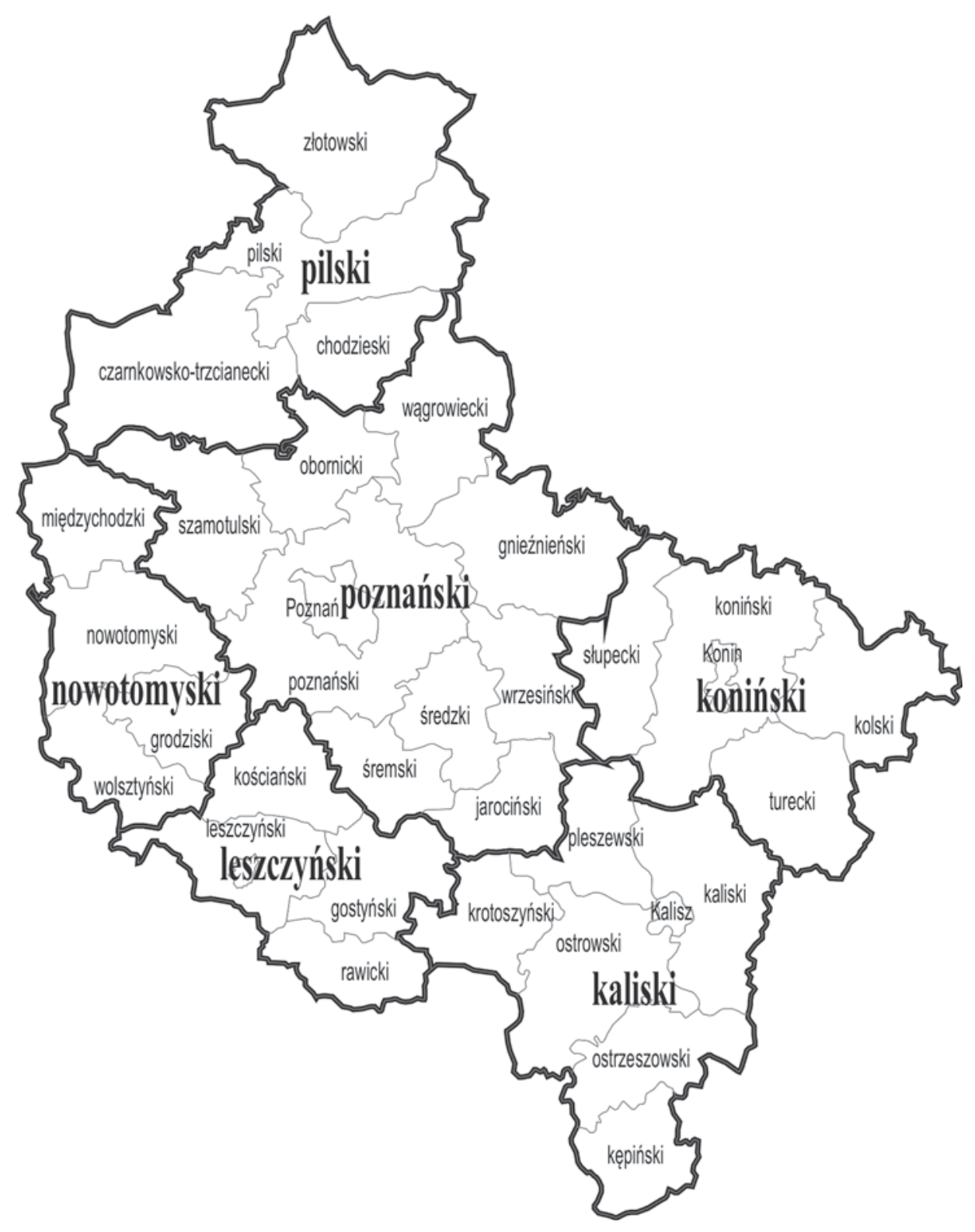

Ryc. 2. Delimitacja obszaru badań na subregiony

Fig. 2. Division of the study area into sub-regions

Źródło: Analiza potrzeb szkoleniowych w zakresie prowadzenia przedsiębiorstw turystycznych oraz świadczenia uslug $w$ sektorze turystycznym $w$ Wielkopolsce, praca wykonana pod kierunkiem Z. Młynarczyka, 2008, s. 5 
Tabela 4. Przedsiębiorstwa turystyczne zarejestrowane w sekcji I w roku 2008

Table 4. Touristic enterprises incorporated in section I in year 2008

\begin{tabular}{|c|c|c|c|c|c|c|}
\hline \multirow{3}{*}{ Powiaty } & \multicolumn{2}{|c|}{ Hotele } & \multirow{2}{*}{\multicolumn{2}{|c|}{$\begin{array}{c}\begin{array}{c}\text { Obiekty noclegowe } \\
\text { pozostałe }\end{array} \\
\text { liczba }\end{array}$}} & \multicolumn{2}{|c|}{ Baza gastronomiczna } \\
\hline & & & & & & \\
\hline & obiektów & $\begin{array}{l}\text { zatrudnio- } \\
\text { nych }\end{array}$ & obiektów & $\begin{array}{l}\text { zatrudnio- } \\
\text { nych }\end{array}$ & obiektów & $\begin{array}{c}\text { zatrudnio- } \\
\text { nych }\end{array}$ \\
\hline \multicolumn{7}{|c|}{ Subregion poznański } \\
\hline gnieźnieński & 20 & 445 & 20 & 111 & 157 & 518 \\
\hline jarociński & 3 & 14 & 3 & 3 & 62 & 201 \\
\hline obornicki & 3 & 30 & 12 & 24 & 27 & 100 \\
\hline $\begin{array}{l}\text { Poznań } \\
\text { (miasto) }\end{array}$ & 114 & 1045 & 197 & 746 & 890 & 4209 \\
\hline poznański & 68 & 584 & 66 & 205 & 342 & 1259 \\
\hline szamotulski & 9 & 133 & 18 & 65 & 62 & 196 \\
\hline średzki & 6 & 62 & 10 & 44 & 52 & 154 \\
\hline śremski & 6 & 29 & 5 & 4 & 33 & 125 \\
\hline wagrowiecki & 3 & 23 & 7 & 26 & 46 & 139 \\
\hline wrzesiński & 8 & 79 & 9 & 31 & 91 & 243 \\
\hline Suma: & 240 & 2444 & 347 & 1259 & 1762 & 7144 \\
\hline \multicolumn{7}{|c|}{ Subregion koniński } \\
\hline Kolski & 3 & 17 & 6 & 32 & 114 & 276 \\
\hline Konin (miasto) & 8 & 47 & 10 & 35 & 130 & 324 \\
\hline koniński & 7 & 150 & 55 & 59 & 119 & 507 \\
\hline słupecki & 5 & 49 & 12 & 20 & 88 & 221 \\
\hline turecki & 2 & 27 & 4 & 29 & 58 & 220 \\
\hline Suma: & 25 & 290 & 87 & 175 & 509 & 1548 \\
\hline \multicolumn{7}{|c|}{ Subregion kaliski } \\
\hline kaliski & 6 & 29 & 4 & 11 & 28 & 79 \\
\hline Kalisz (miasto) & 7 & 47 & 13 & 53 & 98 & 297 \\
\hline kępiński & 3 & 34 & 3 & 21 & 30 & 99 \\
\hline krotoszyński & 7 & 85 & 3 & 2 & 46 & 116 \\
\hline ostrowski & 10 & 188 & 15 & 67 & 129 & 436 \\
\hline ostrzeszowski & 6 & 8 & 8 & 37 & 32 & 73 \\
\hline pleszewski & 4 & 40 & 3 & 14 & 32 & 115 \\
\hline Suma: & 43 & 431 & 49 & 205 & 395 & 1215 \\
\hline
\end{tabular}




\begin{tabular}{|c|c|c|c|c|c|c|}
\hline \multicolumn{7}{|c|}{ Subregion leszczyński } \\
\hline gostyński & 3 & 42 & 2 & 1 & 34 & 106 \\
\hline kościański & 4 & 48 & 7 & 23 & 53 & 215 \\
\hline leszczyński & 3 & 16 & 9 & 12 & 45 & 130 \\
\hline $\begin{array}{l}\text { Leszno } \\
\text { (miasto) }\end{array}$ & 10 & 81 & 11 & 46 & 78 & 278 \\
\hline rawicki & 2 & 46 & 8 & 16 & 34 & 139 \\
\hline Suma: & 22 & 233 & 37 & 98 & 244 & 868 \\
\hline \multicolumn{7}{|c|}{ Subregion nowotomyski } \\
\hline grodziski & 3 & 22 & 5 & 20 & 38 & 148 \\
\hline międzychodzki & 4 & 38 & 11 & 13 & 30 & 85 \\
\hline nowotomyski & 14 & 120 & 20 & 46 & 52 & 189 \\
\hline wolsztyński & 8 & 87 & 13 & 79 & 41 & 85 \\
\hline Suma: & 29 & 267 & 49 & 158 & 161 & 507 \\
\hline \multicolumn{7}{|c|}{ Subregion pilski } \\
\hline chodzieski & 8 & 71 & 2 & 5 & 32 & 113 \\
\hline $\begin{array}{l}\text { czarnkowsko- } \\
\text {-trzcianecki }\end{array}$ & 7 & 90 & 17 & 39 & 44 & 199 \\
\hline pilski & 12 & 171 & 23 & 73 & 113 & 414 \\
\hline złotowski & 7 & 58 & 10 & 22 & 33 & 71 \\
\hline Suma: & 34 & 390 & 52 & 139 & 222 & 797 \\
\hline $\begin{array}{l}\text { Województwo } \\
\text { wielkopolskie }\end{array}$ & 393 & 4055 & 621 & 2034 & 3293 & 12079 \\
\hline
\end{tabular}

Źródło: Główny Urząd Statystyczny, 2008

W ujęciu subregionów (www.izba.pila.pl) zdecydowanie pod względem liczby obiektów świadczących podstawowe usługi turystyczne wyróżnia się subregion poznański (ryc. 3). Subregiony koniński i kaliski prezentują podobną dynamikę, mniejszą pilski i leszczyński, natomiast najmniejszą liczbę tych obiektów odnotowano w subregionie nowotomyskim. W przypadku wszystkich subregionów dominującą kategorią obiektów są restauracje i placówki gastronomiczne, następnie obiekty noclegowe turystyki i miejsca krótkotrwałego zakwaterowania oraz biura podróży, zwłaszcza w takich subregionach, jak poznański i kaliski.

Następnie analogicznie jak w przypadku liczby obiektów turystycznych podobna liczba osób zatrudnionych w analizowanych typach działalności występują w subregionie konińskich i kaliskim oraz pilskim i leszczyńskim, natomiast najniższe $\mathrm{w}$ subregionie nowotomyskim. Największa liczba zatrudnionych także jest związana $\mathrm{z}$ działalnością $\mathrm{w}$ restauracjach i pozostałych placówkach gastronomicznych. Zauważalną tendencją jest większy udział zatrudnionych 


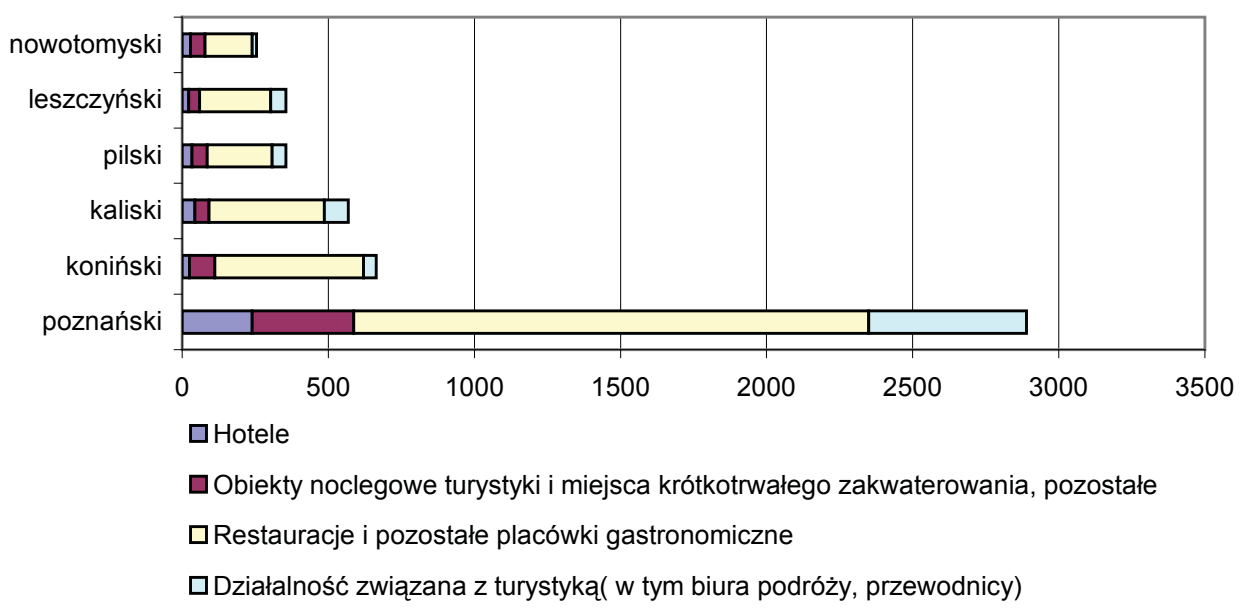

Ryc. 3. Liczba obiektów prowadzących działalność związaną z podstawowymi usługami turystycznymi w Wielkopolsce

Fig. 3. The number of commercial entities offering basic tourist services in the region of Wielkopolska Źródło: Główny Urząd Statystyczny, Poznań, 2008

w hotelach (zwłaszcza w subregionie poznańskim) niż w innych obiektach noclegowych turystyki.

Przedsiębiorstwa turystyczne w Wielkopolsce przede wszystkim nastawione są na świadczenie usług gastronomicznych. W zależności od subregionu w Wielkopolsce różnie kształtuje się przewaga form działalności związanej $\mathrm{z}$ turystyką, $\mathrm{z}$ jednej strony działalnością biur podróży, działalnością przewodnicką, a z drugiej strony oferty obiektów hotelowych oferujących tańsze noclegi w stosunku do hoteli. Subregion poznański, a co się z tym wiąże miasto Poznań są swoistym liderem w ogólnej liczbie przedsiębiorstw turystycznych. Działalność turystyczna w pozostałych subregionach kształtuje się na zbliżonym poziomie.

\section{PODMIOTY NOWO ZAREJESTROWANE I WYREJESTROWANE}

W roku 2008 obserwuje się tendencję wzrostową w zakresie wielkości powstających przedsiębiorstw turystycznych. Zarejestrowanych zostaje znacznie więcej nowych podmiotów gospodarczych w stosunku do wyrejestrowanych (ryc. 4). Znacznym wzrostem odznacza się przede wszystkim sektor prywatny, gdyż w obszarze sektora publicznego wahania wielkości liczby podmiotów 


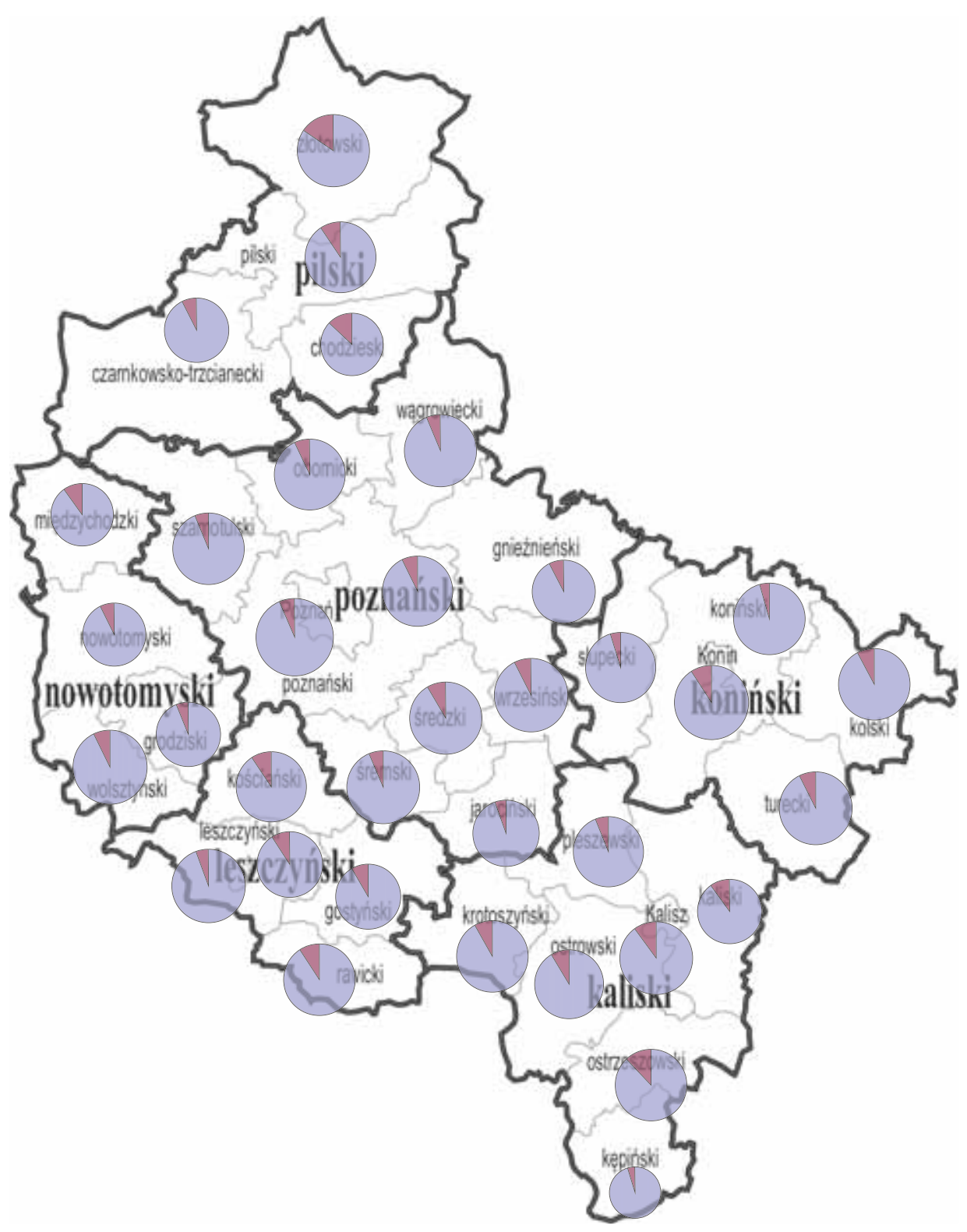

Ryc. 4. Stosunek liczby podmiotów nowo zarejestrowanych do podmiotów wyrejestrowanych Fig. 4. Relation of number of new incorporated subjects for logout subjects Źródło: Na podstawie danych GUS 
leżą w granicach od 1 do 2 podmioty gospodarcze. Tylko w kilku powiatach województwa wielkopolskiego jest niewielka przewaga podmiotów wyrejestrowanych nad nowo zarejestrowanymi (szamotulski, wągrowiecki, jarociński, kępiński, międzychodzki, pleszewski i miasto Leszno).

Działalność podmiotów turystycznych jest ściśle uzależniona od statusu administracyjnego gmin województwa wielkopolskiego. Prywatni inwestorzy zdecydowanie chętniej finansują przedsięwzięcia turystyczne w ośrodkach miejskich, a dopiero później w gminach o charakterze miejsko-wiejskim oraz wiejskim. Zdecydowana większość przedsiębiorstw działa w zakresie szeroko rozumianych usług gastronomicznych, $\mathrm{z}$ przewagą $\mathrm{w}$ największym ośrodku miejskim, jakim jest Poznań. Ponadto, z roku na rok liczba podmiotów gospodarczych działających w zakresie usług turystycznych wzrasta.

\section{LITERATURA}

Duraj J. 2000: Podstawy ekonomiki przedsiębiorstwa. PWE, Warszawa.

Dz.U. 251 z 31 grudnia 2007 r., poz. 1885.

Młynarczyk Z. (pod kierunkiem) 2008: Analiza potrzeb szkoleniowych $w$ zakresie prowadzenia przedsiębiorstw turystycznych oraz świadczenia ustug $w$ sektorze turystycznym $w$ Wielkopolsce. Ekspertyza na zlecenie Departamentu Gospodarki Urzędu Marszałkowskiego Województwa Wielkopolskiego, Poznań.

Szwichtenberg A. 2006: Gospodarka turystyczna polskiego wybrzeża. Ser. Monografie nr 121, Politechnika Koszalińska, Koszalin.

Ustawa z 19.11.1999 r., Prawo działalności gospodarzącej, Dz.U. z 17 grudnia 1999 Nr 101, poz. 1178.

Załącznik do Rozporządzenia Rady Ministrów z 24.12.2007, Dz.U. 251, poz. 1885. 